\title{
Frequency of the Causes of Postmenopausal Bleeding, Results of a Tertiary Referral Center in Turkey
}

\author{
Umit Yasemin SERT 1 , Tuncay NAS ${ }^{2}$, Ismail GULER ${ }^{2}$
}

Ankara, Turkey

\begin{abstract}
OBJECTIVE: In this study, we aimed to determine the frequency of etiologic factors that causes postmenopausal bleeding.

STUDY DESIGN: For the purpose, a total number of 200 women with postmenopausal bleeding were included in the study. Medical records regarding history, physical examination, and endometrium biopsy of these cases were retrospectively analyzed. The frequency of etiologic factors and relevancy of pathological results with demographic factors were determined.
\end{abstract}

RESULTS: Most frequent histopathologic diagnosis of the women with postmenopausal bleeding were established as endometrial atrophy, endometrial polyp, inadequate material, cancer, proliferative endometrium, endometrial hyperplasia, and other disorders respectively. Contrarily the previous studies, our study showed that estrogen replacement therapy was not a reason for postmenopausal bleeding.

CONCLUSION: Although endometrial atrophy is the most frequent cause, postmenopausal bleeding should promptly be evaluated since endometrial hyperplasia and cancer are frequently the underlying cause. We found that premalignant and malignant lesions were related to the patients' BMI (body mass index), duration of postmenopause, the presence of diabetes, determination of thick endometrium by ultrasonography.

\section{Keywords: Atrophy, Estrogen replacement therapy, Postmenopausal bleeding \\ Gynecol Obstet Reprod Med 2021;27(1):65-71}

\section{Introduction}

Menopause can be defined as the cessation of menstrual cycles due to the loss of ovarian function resulting in reduced ovarian production of biologically active estrogen and increasing levels of follicle-stimulating hormone (FSH) (1). Postmenopausal bleeding (PMB) refers to any vaginal bleeding 12 months or more after the last menstrual period (2).

Postmenopausal bleeding is an important medical problem

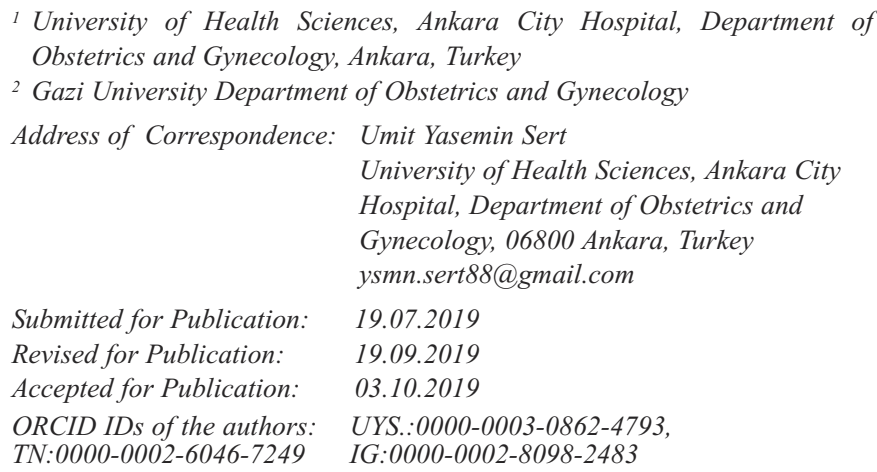

\begin{tabular}{c|c}
\hline Quick Response Code: & Access this article online \\
\cline { 2 - 2 } & Website: www.gorm.com.tr \\
\hline & e- mail: info@gorm.com.tr \\
\cline { 2 - 2 } & DOI:10.21613/GORM.2019.1007 \\
\hline
\end{tabular}

How to cite this article: Sert UY. Nas T. Guler I. Frequency of the Causes of Postmenopausal Bleeding, Results of a Tertiary Referral Center in Turkey. Gynecol Obstet Reprod Med 2021;27(1):65-71 affecting almost $10 \%$ of the general population (3). In our country, the average age for menopause is 47 according to the comments of the Turkish Association of Menopause and Osteoporosis (4), while the median age at menopause among women living in developed countries ranges between 50-52 years (5). Factors associated with the timing of menopause are race, ethnicity, demographic features, and lifestyle, as well as genetic factors (5).

The endometrium is expected to be atrophic during the postmenopausal period and women with unexpected uterine bleeding should be evaluated carefully to be able to detect potential underlying causes such as gynecologic malignancies (6). Endometrial carcinoma, which is a potentially lethal disease, is the cause of bleeding in approximately 10 percent (range 3.7 to 17.9 percent) of bleeding women $(7,8)$. Although the most common cause of bleeding in these women is atrophy of the vaginal mucosa or endometrium, postmenopausal bleeding can be rarely thought as a result of vulvar, vaginal or cervical cancers, including uterine sarcomas, and can also be related to ovarian pathologies (9). Early diagnosis may improve disease outcomes, hence several diagnostic procedures for clinical investigation have been studied in the literature (5).

In this study, we purposed to identify underlying causes of postmenopausal bleeding, frequencies of the symptom, and to demonstrate the relationship between age, parity, body mass index (BMI), postmenopausal duration, diabetes, hyperten- 
sion, hormone replacement therapy (HRT), tamoxifen use, smoking, alcohol use and endometrial thickness.

\section{Material and Method}

To determine the frequency of underlying causes of postmenopausal bleeding, 200 patients who were admitted to the Gazi University Obstetrics and Gynecology Department between 01.01.2014 - 01.01.2016 with complaints of vaginal bleeding episodes seen $\geq 12$ months after the last menstrual period were evaluated retrospectively. The ethics committee of Numune Education and Research Hospital has approved the study protocol (07.01.2015*E15-389) which the work was undertaken and it conforms to the provisions of the Declaration of Helsinki (as revised in Fortaleza, Brazil, October 2013).

Detailed anamnesis of patients was obtained from the medical records. Systemic and pelvic examinations, cervical smear samples and specific ultrasonography findings were noted. All of the patients were evaluated by at least one of either pipelle, fractional curettage (endocervical and endometrial curettage) and hysteroscopy procedures for histopathological determination.

Data analysis was performed with IBM SPSS Statistics 17.0 package software (IBM Corporation, Armonk, NY, USA). Kolmogorov-Smirnov test was used to determine whether the distribution of continuous variables was close to normal. Descriptive statistics were expressed as mean \pm standard deviation or median (minimum-maximum) for continuous variables, and categorical variables were presented as the number of cases and (\%). The significance of differences between groups for averages was investigated with Student's ttest and the significance for median values by Mann-Whitney U-test. Categorical variables were assessed using Continuity Correction Chi-Square or Fisher's Exact Probability test and the results were considered statistically significant for $p<0.05$.

\section{Results}

In this study, clinical and pathologic findings of 200 patients who were admitted to the Gazi University Obstetrics and Gynecology Department between 01.01.2014-01.01.2016

Table I: Frequency distributions of cases in terms of diagnosis

\begin{tabular}{lcc}
\hline Diagnosis & Patients (n) & $\%$ \\
\hline Atrophy & 76 & 38.0 \\
Endometrial polyp & 46 & 23.0 \\
Proliferative endometrial fragments & 48 & 24.0 \\
Myoma uteri & 3 & 1.5 \\
Inadequate material & 2 & 1.0 \\
Squamous metaplasia & 1 & 0.5 \\
Endometritis & 1 & 0.5 \\
Simple hyperplasia & 1 & 0.5 \\
Complex hyperplasia with atypia & 2 & 1.0 \\
Complex hyperplasia without atypia & 2 & 1.0 \\
Malignancy & 18 & 9.0 \\
Total & 200 & 100 \\
\hline
\end{tabular}

with complaints of postmenopausal vaginal bleeding were evaluated retrospectively.

Frequency distributions of the histopathologic diagnoses of 200 postmenopausal bleeding cases were evaluated in the study (Table I).

Histopathologic results of the patients in the study group were divided into two sub-groups: premalignant+malignant group and benign group. In the premalignant + malignant group, malignancy, simple hyperplasia without atypia, complex hyperplasia without atypia, simple atypical hyperplasia, and complex atypical hyperplasia were examined according to the World Health Organization (WHO) classification of hyperplasia. In the benign group, other histopathologic results were investigated. There were 177 patients in the benign group and 23 patients in the premalignant+malignant group.

Table II compares the demographic and clinical characteristics of the cases according to the diagnostic groups. According to these results, a statistically significant difference was found between groups in terms of BMI, menopause duration and endometrial thickness. The median endometrium thickness of the premalignant + malignant group was also statistically higher than that of the benign group $(p<0.001)$ (Figure 1). Endometrial thicknesses according to diagnoses are presented in Table III.

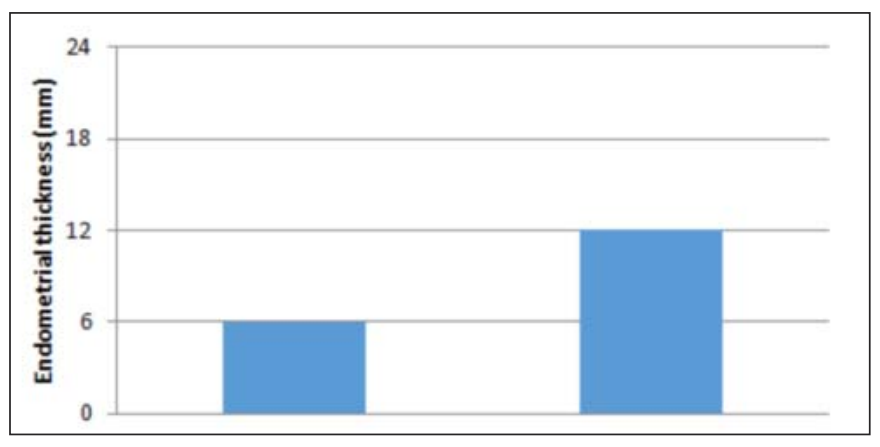

Figure 1: Average endometrial thicknesses of benign and premalignant+malignant groups

Table IV compares coexistent disease, fasting blood glucose (FBG) level, and smoking history of the cases according to the diagnostic groups. Diabetes mellitus (DM) frequency was significantly different between the two groups $(31.1 \%$ vs. $56.5 \%, p=0.029$ ) but there were no statistically significant differences between the two groups in terms of other variables. Diabetes mellitus was statistically more common in the premalignant + malignant group when compared to the benign group. There was no statistical difference between the two groups in terms of the use of Oral contraceptive pills (OCPs) and tamoxifen. The use of an intrauterine device (IUD) was found to be $47.8 \%$ in the premalignant + malignant group and $18.1 \%$ in the benign group and the difference between these two groups was found to be statistically significant $(\mathrm{p}=0.003)$ (Figure 2). 
Table II: Demographic and clinical characteristics of cases according to diagnosis groups

\begin{tabular}{lccc}
\hline Variable & Benign $(\mathrm{n}=177)$ & Premalign+Malignant $(\mathrm{n}=23)$ & $p$ \\
\hline Age $($ year) & $58.3 \pm 6.7$ & $61.4 \pm 8.4$ & $0.102 \dagger$ \\
BMI $\left(\mathrm{kg} / \mathrm{m}^{2}\right)$ & $28.4 \pm 2.8$ & $30.0 \pm 3.1$ & $0.014 \dagger$ \\
Menopause (year) & $5(1-35)$ & $10(1-35)$ & $0.034 \ddagger$ \\
Reproductive period (year) & $37(25-46)$ & $36(20-40)$ & $0.172 \ddagger$ \\
Gravidity & $4(0-11)$ & $4(0-10)$ & $0.285 \ddagger$ \\
Parity & $3(0-9)$ & $3(0-9)$ & $0.226 \ddagger$ \\
Endometrial thickness $(\mathrm{mm})$ & $6(2-24)$ & $12(4-20)$ & $0.000 \ddagger$ \\
\hline
\end{tabular}

† Student's t test, $¥$ Mann Whitney $\cup$ test

Table III: Descriptive statistics of endometrium thicknesses according to diagnoses

\begin{tabular}{|c|c|c|c|c|c|}
\hline Diagnosis & Mean (mm) & Std.deviation $( \pm)$ & Median & Min & Max \\
\hline Atrophy & 5.1 & 2.80 & 4.5 & 2.0 & 20.0 \\
\hline Endometrial polyp & 9.2 & 3.88 & 9.0 & 3.0 & 24.0 \\
\hline Proliferative endometrium & 5.8 & 2.10 & 5.5 & 3.0 & 10.0 \\
\hline Myoma uteri & 12.3 & 5.51 & 12.0 & 7.0 & 18.0 \\
\hline Inadequate material & 5.0 & 2.83 & 5.0 & 3.0 & 7.0 \\
\hline Squamous metaplasia & 8.0 & - & 8.0 & 8.0 & 8.0 \\
\hline Endometritis & 4.0 & - & 4.0 & 4.0 & 4.0 \\
\hline Simple hyperplasia & 15.0 & - & 15.0 & 15.0 & 15.0 \\
\hline Complex hyperplasia with atypia & 8.0 & 0.00 & 8.0 & 8.0 & 8.0 \\
\hline Complex hyperplasia without atypia & 8.0 & 5.66 & 8.0 & 4.0 & 12.0 \\
\hline Malignancy & 13.1 & 3.56 & 12.0 & 7.0 & 20.0 \\
\hline Mean & 7.2 & 3.96 & 6.0 & 20 & 24.0 \\
\hline
\end{tabular}

Table IV: Breakdown of cases by coexistent disease, fasting blood glucose level and smoking history according to diagnosis groups and oral contraseptive pills, intrauterine device and Tamoxifen use

\begin{tabular}{lccc}
\hline Variables $(\mathrm{n})(\%)$ & Benign $(\mathrm{n}=177)$ & Premalignant+Malignant $(\mathrm{n}=23)$ & $p$ \\
\hline Diabetes & $55(31.1 \%)$ & $13(56.5 \%)$ & $0.029 \dagger$ \\
Hypertension & $64(36.2 \%)$ & $10(43.5 \%)$ & $0.649 \dagger$ \\
Hypothyroidism & $4(2.3 \%)$ & $1(4.3 \%)$ & $0.461 \ddagger$ \\
Fasting plasma glucose>95mg/dl & $72(40.7 \%)$ & $12(52.2 \%)$ & $0.409 \dagger$ \\
Smoking & $13(7.3 \%)$ & $0(0.0 \%)$ & $0.370 \ddagger$ \\
OCP & $62(35.0 \%)$ & $8(34.8 \%)$ & $1.000 \dagger$ \\
IUD & $32(18.1 \%)$ & $11(47.8 \%)$ & $0.003 \ddagger$ \\
Tamoxifen & $10(5.6 \%)$ & $0(0.0 \%)$ & $0.609 \ddagger$ \\
\hline
\end{tabular}

OCP: Oral contraseptive pills, IUD: Intrauterine device, $\dagger$ Student's $t$ test, $\ddagger$ Mann Whitney $U$ test

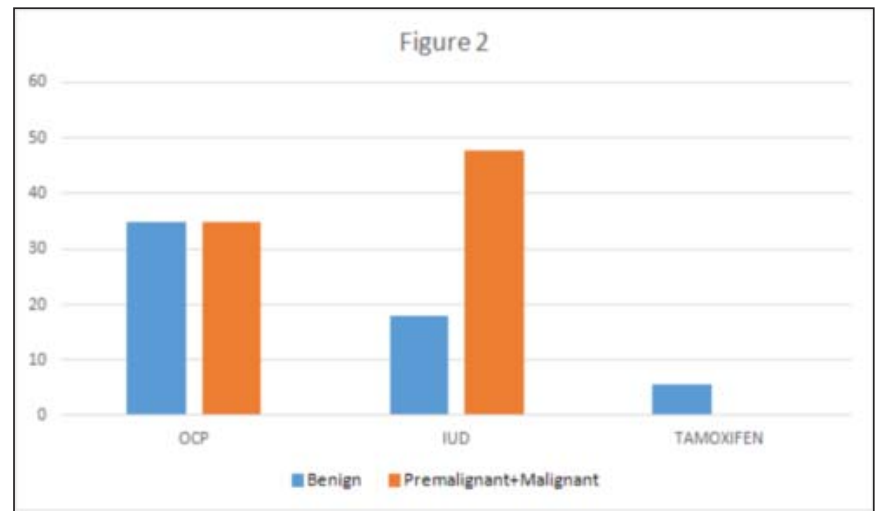

Figure 2: Comparison of groups in terms of oral contraseptive pills, intrauterine device and tamoxifen use

\section{Discussion}

The demographic, clinical and pathologic data of 200 patients who were admitted to our clinic with complaints of postmenopausal bleeding were examined retrospectively and the possible relationship between PMB and these features was investigated.

In a recent study by Astrup et al, the spontaneous postmenopausal bleeding rate was found to be $10.7 \%$ (10). Although several factors may affect the timing, the incidence of postmenopausal bleeding was found to be highest after the first 12-month amenorrhea period and gradually decreased 
after 3 years (10). The average menopause duration of postmenopausal bleeding patients included in our study was 5.57, which was similar to the value in the literature (10). The median menopausal period of the premalignant + malignant group was significantly higher than that of the benign group. According to this result, while a postmenopausal bleeding episode was detected more frequently in the first 5 years after menopause, the probability of detecting an underlying malignancy increased significantly with increasing menopausal period. Van Dorn et al. also demonstrated that premalignant and malignant findings considerably increase with advancing age and time since menopause among women with PMB (11).

Endometrial atrophy, which is the most common reason, was detected in 76 (38\%) of 200 postmenopausal bleeding cases in our study. Similarly, in the literature, it is reported that $60-80 \%$ of PMB cases are endometrial atrophy, $15-25 \%$ exogenous estrogens, $2-12 \%$ endometrial polyp, 5-10\% endometrial hyperplasia, and 10\% endometrial cancer (12).

According to the results obtained from our study, endometrial atrophy is the most frequent histopathological diagnosis in the postmenopausal bleeding cases, although its incidence was lower compared to the literature (13). As a matter of course, as the post-menopausal period extends, the likelihood of detecting the result of a biopsy obtained due to postmenopausal bleeding as atrophy increases significantly (14). The reason for the rate found in our study for the incidence of endometrial atrophy can be explained by the average menopause duration of the patient group participating in the study. The time since menopause is less than the other studies (5.7 years on average) with more frequent endometrial atrophy (15).

Endometrial polyps are common pathologies for all ages, however, the incidence of endometrial polyps increases significantly especially after 50 years of age (16). We found that endometrial polyps constitute $23 \%$ of PMB cases. A total of 46 endometrial polyp cases were detected, twenty (43.4\%) of these were referred to probe curettage and 19 (41.3\%) of these to hysteroscopy. Resection of endometrial polyps using a hysteroscopy method is accepted as the most appropriate method in the literature (17). Endometrial polyps constitute $2-12 \%$ of PMB cases according to the literature while we determined a quite higher rate of $23 \%$ (12). The high rate in our study may also be related to the widespread use of hysteroscopy in our clinic.

Endometrial hyperplasia, which is demonstrated to be 5$10 \%$ of PMB cases in the literature (12), was found to be $2.5 \%$ in our study and atypical hyperplasia was detected in only 2 cases $(1 \%)$. Since this is an estrogen-dependent condition, identified risk factors for endometrial hyperplasia include conditions that cause exogenous estrogen stimulation such as unopposed estrogen therapy, tamoxifen therapy and endogenous estrogen stimulation such as obesity, anovulation and estrogen-producing tumors (18). The decrease in the rate of hyper- plasia defined in the literature may be associated with a possible decrease in the use of exogenous estrogens in our society.

In our study, malignancy was found in 18 cases $(9 \%)$, which is consistent with the $10 \%$ rate in the literature (12). Postmenopausal bleeding is a substantial symptom for the reason that it might be the first and mostly the only symptom of gynecologic malignancy (19). The main purpose of further evaluation of postmenopausal bleeding is to rule out the possibility of an underlying malignancy. In the literature, endometrial cancer (EC) is found at a rate of $4-24 \%$ in patients with postmenopausal bleeding (9). Salman et al. demonstrated that EC was found in $12 \%$ of patients with complaints of PMB (3). The slight increase in the EC rate is attributed to the fact that our center is a referral hospital and therefore EC cases are more frequent.

Many studies on women complaining of PMB demonstrated that endometrial cancer risk increases with advancing age (11). In a recent study evaluating postmenopausal bleeding, Fistonic et al. found that the average age was significantly higher in the cancer group than the endometrial atrophy group and that the average age in the EC group was 62 (20). In this study, the average age was $58.3 \pm 6.7$ in the benign group, which also includes atrophy and $61.4 \pm 8.4$ in the premalignant + malignant group. Phillip et al. found that there was a strong relationship between $>65$ age and EC risk, but this relationship was not significant under the age of 65 (21). We found that the average age of all patients included in the study was $58.6 \pm 6.4$ and the relationship between malignancy and age was not statistically significant for the patients under the age of 65 , which supports the literature.

The increase in the risk of endometrium cancer seen in patients with high BMI is related to the elevation of circulating estrone, which is the main serum estrogen in postmenopausal and obese patients (22). Estrone is produced by aromatization of androgens in peripheral tissues. This transformation is most prevalent in muscle and fatty tissues. While estrone binds weakly to estrogen receptors, an estrogenic effect becomes apparent as a result of a permanent effect. Also, SHBG levels decrease in obese women. This causes an increase in free estrogen levels, which strengthens the estrogenic effect (22). The mean BMI of the patients participating in the study was $28.4 \pm 2.8$ in the benign group and $30.0 \pm 3.1$ in the premalignant + malignant group. Based on these results, the average body mass index of the premalignant+malignant group was found to be statistically higher than that of the benign group. These results support the literature and it can be concluded that the increased BMI is associated with an increase in the incidence of premalignant and malignant lesions. In a study conducted by Shaw et al, obesity was associated with a 4.7-fold increased risk of EC compared to normal-weight women (23).

The median menopausal periods of the patients included in this study were calculated as 5 (1-35) in the benign group and 
$10(1-35)$ in the premalignant + malignant group. The median menopausal period of the premalignant + malignant group was found to be significantly higher than that of the benign group. Similarly, Bruchim et al. conducted a study consisting of patients with postmenopausal bleeding. The study demonstrated that if the menopausal period was $<5$ years, the EC incidence was $2.6 \%$ while the incidence increased to $21.4 \%$ when the menopausal period was $>15$ years. The study clearly stated that the duration of the menopausal period is a statistically significant risk factor for EC (24).

Endometrial thickness is one of the most important factors to detect high-risk patients for underlying malignancy (25). Mean endometrial thickness was $6 \mathrm{~mm}(2-24 \mathrm{~mm})$ in the benign group and $12 \mathrm{~mm}(4-20 \mathrm{~mm})$ in the premalignant + malignant group. The median endometrium thickness of the premalignant+malignant group was also statistically higher than that of the benign group. According to these results, we can conclude that as endometrial thickness increases, the incidence of severe endometrial pathologies will increase. Endometrial thickness was $>5 \mathrm{~mm}$ in all patients with pathology results of malignancy. In a Nordic Multicenter study of 1168 cases, Karlsson et al. found that endometrial thickness was $3.9 \pm 2.5$ $\mathrm{mm}$ in women with atrophic endometrium and $21.11+11.8$ $\mathrm{mm}$ in women with endometrial cancer. In the same study, no endometrial cancer was detected below $5 \mathrm{~mm}$, when $5 \mathrm{~mm}$ was taken as the threshold value. The endometrial pathology rate under $5 \mathrm{~mm}$ was $5.5 \%$, and the sensitivity of TVU to detect endometrial pathologies was $96 \%$ (26). In a meta-analysis of 5892 cases involving 35 prospective studies, SmithBindman et al. found a $1 \%$ chance of EC development in postmenopausal hemiplegic patients with an endometrial thickness thinner than $5 \mathrm{~mm}$. In our study, when the threshold value of endometrial thickness was assumed as $5 \mathrm{~mm}$, the sensitivity of TVU to detect endometrial pathology was $86 \%$ and the specificity was $28 \%$, which is consistent with the studies in the literature.

Diabetes mellitus was observed in $55(31.1 \%)$ patients in the benign group. Our study demonstrated that there were 13 (56.5\%) patients with $\mathrm{DM}$ in the premalignant+malignant group and the difference between the two groups was statistically significant $(p=0.029)$. The DM history in the premalignant+malignant group was statistically more common compared to the benign group. In the literature, DM is also considered as a risk factor for endometrial malignancy (27-32). In 2014, Luo et al. published a study involving 88,107 postmenopausal patients. After an average follow-up of 11 years, 1.241 ECs developed and the patients were examined taking into account the presence of DM and their BMI. The results suggest that DM is a risk factor for EC due to increased BMI (33). The results of our study support the literature.

Although studies have shown that the use of hormone-free IUD reduces the incidence of $\mathrm{EC}$, there are also opinions that a foreign body settled into the endometrium may increase the risk with long-term use due to potential trauma to the endometrial surface (34). Studies have shown that hormonal IUDs can be used for the treatment of premalignant and earlystage malignancies and the use of IUD reduces the risk of EC. It is assumed to provide this function by inhibiting endometrial hyperplasia and promoting endometrial atrophy (35). In our study, the use of IUD was $47.8 \%$ in the premalignant + malignant group and $18.1 \%$ in the benign group and the difference between the two groups was statistically significant ( $p=0.003$ ). This result suggests that the use of IUD is higher in the premalignant + malignant group than in the benign group, which is inconsistent with the literature. Further studies are needed on this field.

Exogenous estrogens affect the endometrium, which is shown at a rate of $15-25 \%$ in the literature (12). None of the patients included in our study were receiving estrogen replacement therapy. Although estrogen deficiency symptoms (vaginal dryness, hot flushes, osteoporosis, increased risk of cardiovascular disease) can be handled by estrogen replacement, less than $20 \%$ of postmenopausal women use estrogen because of the possible risks of HRT (36). The results of the Women's Health Initiative (WHI) study was finished in 2004. The study showed that estrogen alone did not significantly affect breast cancer and heart disease when compared to placebo, but estrogen+progesterone treatment increased stroke risk when compared to estrogen alone (37). In the Million Women Study conducted in 2003, the relative risk of breast cancer was found to increase with the use of HRT (38). In light of this information, the general view is that the use of HRT should be individualized, taking into account the possible risks. There has been a marked decline in the use of HRT in recent years, especially with the publication of studies emphasizing that it has conflicting effects on cardiovascular disease (benefits have been shown in younger women for their early menopausal period while studies have shown harmful effects for elderly women) (39). We believe that our study is discordant with the literature in this aspect because the studies focusing on postmenopausal bleeding etiology have not been updated recently in the literature.

We believe that the advanced treatment modalities and awareness of the prevention, risk factors and symptoms of gynecologic premalignant and malignant lesions and decreasing use of HRT are the main reasons for the modifications in the distribution of underlying pathologies. Secondary results of our study show that the likelihood of malignancy as the cause of postmenopausal bleeding increases with increased BMI, duration of menopausal period, endometrial thickness, presence of diabetes and the use of IUD.

\section{Conclusion}

In this study, different results were found compared to the 
literature in the breakdown of etiological causes due to the effect of drawbacks in the use of hormone replacement therapies in recent years. Accordingly, there was no statistically significant relationship between age, reproductive time, gravida, parity, hypertension, OCS and tamoxifen use, and premalignant + malignant lesions. Menopausal period, BMI, presence of $\mathrm{DM}$, an increase of endometrial thickness and use of IUD were found to be associated with premalignant + malignant lesions.

\section{Acknowledgments: "None" \\ Funding Statement: "None"}

Disclosures: The authors report no conflicts of interest. Author Contribution: UYS conducted the literature searches and participated in data analyses and wrote the initial draft, $I G$ participated in data analyses and revised the draft manuscript intellectual content. TN conceived and designed the study, contributed the data analyses, and revised the manuscript. All authors have contributed significantly to this study, all authors agree with the content of the manuscript and approved the final version of the paper. All authors participated in all the works needed for preparing the final shape of this original research. Concept, design and all comments of this original research are prepared and established by all of the authors as active participants.

\section{References}

1. Gosden RG. Biology of menopause: the causes and consequences of ovarian ageing: Academic Pr; 1985. Comparative Biochemistry and Physiology Part A: Physiology. 1986;83(4):798.

2. Rodger F. Walker J. Critchley H. Investigating the woman with postmenopausal bleeding. Trends In UGSH. 2005;10:1-4.

3. Salman MC. Bozdag G. Dogan S. Yuce K. Role of postmenopausal bleeding pattern and women's age in the prediction of endometrial cancer. Aust N Z J Obstet Gynaecol. 2013;53(5):484-8. doi: 10.1111/ajo.12113.

4. Ceylan B. Ozerdogan N. Factors affecting age of onset of menopause and determination of quality of life in menopause. Turk J Obstet Gynecol. 2015;12(1):43-9.doi: 10.4274/tjod.79836.

5. Gold EB. The timing of the age at which natural menopause occurs. Obstet Gynecol Clin North Am. 2011;38(3):425-40. doi: 10.1016/j.ogc.2011.05.002.

6. Cho HJ. Lee ES. Lee JY. Hong SN. Ji YI. Kim HY. et al. Investigations for postmenopausal uterine bleeding: special considerations for endometrial volume. Arch Iran Med. 2013;16(11):665-70.

7. Epstein E. Ramirez A. Skoog L. Valentin L. Transvaginal sonography, saline contrast sonohysterography and hysteroscopy for the investigation of women with postmenopausal bleeding and endometrium $>5 \mathrm{~mm}$. Ultrasound Obstet Gynecol. 2001;18(2):157-62. doi: 10.1046/j.1469-0705.2001.00472.x.
8. Epstein E. Ramirez A. Skoog L, Valentin L. Dilatation and curettage fails to detect most focal lesions in the uterine cavity in women with postmenopausal bleeding. Acta Obstet Gynecol Scand. 2001;80(12):1131-6. doi: 10.1034/j.1600-0412.2001.801210.x.

9. Oriel KA. Schrager S. Abnormal uterine bleeding. Am Fam Physician. 1999;60(5):1371-80; discussion 1381-2.

10. Astrup K, Olivarius Nde F. Frequency of spontaneously occurring postmenopausal bleeding in the general population. Acta Obstet Gynecol Scand. 2004;83(2):203-7.

11. van Doorn HC. Opmeer BC. Jitze Duk M. Kruitwagen RF, Dijkhuizen FP, Mol BW. The relation between age, time since menopause, and endometrial cancer in women with postmenopausal bleeding. Int $\mathrm{J}$ Gynecol Cancer. 2007;17(5):1118-23. doi:10.1111/j.1525-1438.2007. 00925.x.

12. Otify M. Fuller J. Ross J. Shaikh H. Johns J. Endometrial pathology in the postmenopausal woman-an evidence based approach to management. Obstet Gynaecol. 2015; 17(1):29-38. do i:10.1111/tog.12150.

13. Guido R. Kanbour-Shakir A. Rulin MC. Christopherson WA. Pipelle endometrial sampling. Sensitivity in the detection of endometrial cancer. J Reprod Med. 1995;40 (8):553-5.

14. Elkholi DGE. Nagy HM. Unexplained postmenopausal uterine bleeding from atrophic endometrium: Histopathological and hormonal studies. Middle East Fertil Soc J. 2015;20(4):262-70.

15. Sheng J. Chen Y. Pan J. Combining transvaginal sonography and endometrial cytology in the diagnosis of endometrial disorders in postmenopausal women. Zhonghua $\mathrm{Fu}$ Chan Ke Za Zhi. 2001;36(6):341-3.

16. Cravello L. Stolla V. Bretelle F. Roger V. Blanc B. Hysteroscopic resection of endometrial polyps: a study of 195 cases. Eur J Obstet Gynecol Reprod Biol. 2000; 93(2):131-4. doi: 10.1016/s0301-2115(00)00281-5.

17. Reslova T. Tosner J. Resl M. Kugler R. Vavrova I. Endometrial polyps. A clinical study of 245 cases. Arch Gynecol Obstet. 1998;262(3-4):133-9. doi: 10.1007/ s004040050241.

18. Linkov F. Edwards R. Balk J. Yurkovetsky Z. Stadterman B. Lokshin A. et al. Endometrial hyperplasia, endometrial cancer and prevention: gaps in existing research of modifiable risk factors. Eur J Cancer. 2008;44(12):1632-44. doi: 10.1016/j.ejca.2008.05.001.

19. Dimitraki M. Tsikouras P. Bouchlariotou S. Dafopoulos A. Liberis V. Maroulis G. et al. Clinical evaluation of women with PMB. Is it always necessary an endometrial biopsy to be performed? A review of the literature. Arch Gynecol Obstet. 2011;283(2):261-6. doi: 10.1007/s00404010-1601-3.

20. Fistonic I. Hodek B. Klaric P. Jokanovic L. Grubisic G. Ivicevic-Bakulic T. Transvaginal sonographic assessment 
of premalignant and malignant changes in the endometrium in postmenopausal bleeding. $\mathrm{J}$ Clin Ultrasound. 1997;25(8):431-5. doi: 10.1002/(sici)10970096(199710)25:8<431::aid-jcu4>3.0.co;2-k.

21. Phillip H. Dacosta V. Fletcher H. Kulkarni S. Reid M. Correlation between transvaginal ultrasound measured endometrial thickness and histopathological findings in Afro-Caribbean Jamaican women with postmenopausal bleeding. J Obstet Gynaecol. 2004;24(5):568-72. doi: $10.1080 / 01443610410001722671$.

22. Karim R. Mack WJ. Hodis HN. Roy S. Stanczyk FZ. Influence of age and obesity on serum estradiol, estrone, and sex hormone binding globulin concentrations following oral estrogen administration in postmenopausal women. J Clin Endocrinol Metab. 2009;94(11):4136-43. doi: 10.1210/jc.2009-0643.

23. Shaw E. Farris M. McNeil J. Friedenreich C. Obesity and Endometrial Cancer. Recent Results Cancer Res. 2016;208:107-36. doi: 10.1210/jc.2009-0643.

24. Bruchim I. Biron-Shental T. Altaras MM. Fishman A. Beyth Y. Tepper R. et al. Combination of endometrial thickness and time since menopause in predicting endometrial cancer in women with postmenopausal bleeding. J Clin Ultrasound.2004;32(5):219-24. doi: 10.1002/ jcu. 20020 .

25. Karasu AFG. Ates S. Gurbuz T. Sahin N. Takmaz T. Aydin S. A Clinico-pathological Study of Transvaginal Endometrial Thickness Measurement in Asymptomatic Postmenopausal Patients and Patients with Postmenopausal Bleeding. Gynecol Obstet Reprod Med. 2019:25(2):85-8. doi: https://doi.org/10.21613/GORM. 2018.851

26. Karlsson B. Granberg S. Wikland M. Ylöstalo P. Torvid K. Marsal K. et al. Transvaginal ultrasonography of the endometrium in women with postmenopausal bleeding-a Nordic multicenter study. Am J Obstet Gynecol. 1995; 172(5):1488-94. doi: 10.1016/0002-9378(95)90483-2.

27. Weber AM. Belinson JL. Piedmonte MR. Risk factors for endometrial hyperplasia and cancer among women with abnormal bleeding. Obstet Gynecol. 1999;93(4):594-8. doi: 10.1016/s0029-7844(98)00469-4.

28. Strinić T. Buković D. Bilonić I. Hirš I. Despot A. Boćan A. Socio-demographic characteristics of women with endometrial carcinoma. Coll Antropol. 2003;27 Suppl 1:55-9.

29. Weiderpass E. Persson I. Adami HO. Magnusson C.
Lindgren A. Baron JA. Body size in different periods of life, diabetes mellitus, hypertension, and risk of postmenopausal endometrial cancer (Sweden). Cancer Causes Control. 2000;11(2):185-92. doi:10.1023/a:100894682 5313.

30. Parazzini F. La Vecchia C. Negri E. Luca Riboldi GL. Surace M. Benzi G. et al. Diabetes and endometrial cancer: An Italian case-control study. Int J Cancer. 1999;81(4):539-42. doi:10.1002/(sici)1097-0215(1999 0517) $81: 4<539:$ :aid-ijc6>3.0.co;2-q.

31. Anderson KE. Anderson E. Mink PJ. Hong CP. Kushi LH. Sellers TA. et al. Diabetes and endometrial cancer in the Iowa women's health study. Cancer Epidemiol Biomarkers Prev. 2001;10(6):611-6.

32. Gerber J. Sozański L. Suchocki S. The risk factors of endometrial cancer. Ginekol Pol. 2001;72(12A):1418-22.

33. Luo J. Beresford S. Chen C. Chlebowski R. Garcia L. Kuller L. et al. Association between diabetes, diabetes treatment and risk of developing endometrial cancer. Br J Cancer. 2014;111(7):1432-9. doi: 10.1038/bjc.2014.407.

34. Felix AS. Gaudet MM. La Vecchia CL. Nagle CM. Shu XO. Weiderpass E. et al. Intrauterine devices and endometrial cancer risk: a pooled analysis of the Epidemiology of Endometrial Cancer Consortium. Int J Cancer. 2015;136(5):E410-22. doi: 10.1002/ijc.29229.

35. Benshushan A. Paltiel O. Rojansky N. Brzezinski A. Laufer N. IUD use and the risk of endometrial cancer. Eur J Obstet Gynecol Reprod Biol. 2002;105(2):166-9. doi: 10.1016/s0301-2115(02)00153-7.

36. Cauley JA. Cummings SR. Black DM. Mascioli SR. Seeley DG. Prevalence and determinants of estrogen replacement therapy in elderly women. Am J Obstet Gynecol. 1990;163(5 Pt 1):1438-44. doi: 10.1016/00029378(90)90602-4

37. Wildemeersch D. Safety and comfort of long-term continuous combined transdermal estrogen and intrauterine levonorgestrel administration for postmenopausal hormone substitution-a review. Gynecol Endocrinol. 2016:32(8): 598-601. doi: 10.1080/09513590.2016.1177014.

38. Gray S. Breast cancer and hormone-replacement therapy: the Million Women Study. Lancet. 2003;362(9392):1332; author reply 1332. doi: 10.1016/S0140-6736(03)14598-9.

39. Stevenson JC. Establishing the risk related to hormone replacement therapy and cardiovascular disease in women. Suicide. 2019;14:20. 